\title{
Deviasi Taksiran Berat Janin pada Metode Johnson-Toshack, Formula Sederhana dan Formula Dare
}

\author{
Emy Rianti ${ }^{1}$, Siti Aminah ${ }^{2}$ \\ ${ }^{1,2}$ Jurusan Kebidanan, Politeknik Kesehatan Kemenkes Jakarta I \\ Email: emyrianti@gmail.com
}

\begin{abstract}
The Deviation of Fetal Weight Estimation According to Johnson-Toshack Method, Simple Formula, and Dare formula. The ability of the birth attendant to estimate the birth weight of the fetus is very important that it does not cause childbirth dystocia that may cause a rip in the birth canal. The aim of this study was to compare the deviation of fetal weight estimation according to Johnson-Toshack method, simple formula, and Dare formula. The design used was cross sectional, the data were taken primarily, involving 100 respondents at Fatmawati General Hospital Jakarta, from August to September 2015. The findings showed that the smallest deviation mean of fetal weight estimation is Johnson-Toshack method. The results of this method of measurement tend to be close to infant birth weight, especially in the client childbirth with abdominal circumference $90-100 \mathrm{~cm}$. The conclusion of this study is that Johnson-Toshack's fetal weighing estimates are more appropriate for childbirth with 90 to $100 \mathrm{~cm}$ abdominal circumference size, except in childbirth with ruptured membranes, applying a fetal weight estimate based on the Dare formula would be more appropriate.
\end{abstract}

Keywords: Fetal Weight Estimation, Johnson-Toshack Method, Simple's Formula, Dare's Formula

\begin{abstract}
Abstrak: Deviasi Taksiran Berat Janin (TBJ) menurut Metode Johnson-Toshack, Formula Sederhana dan Formula Dare. Kemampuan penolong persalinan menaksir berat badan lahir janin sangat penting sehingga tidak menimbulkan distosia persalinan yang bisa menyebabkan robekan jalan lahir. Penelitian ini bertujuan membandingkan deviasi perhitungan taksiran berat janin (TBJ) menurut metode Johnson-Toshack, formula sederhana dan formula Dare. Desain yang digunakan adalah potong lintang, data diambil secara primer, melibatkan 100 responden di RSUP Fatmawati Jakarta, pada Agustus - September 2015. Hasil temuan didapatkanbahwa rerata deviasi terkecil dari pengukuran TBJ adalah metode Johnson-Toshack. Hasil pengukuran metode ini cenderung mendekati berat badan lahir bayi, khususnya pada klien persalinan dengan ukuran lingkar perut 90-100 cm. Kesimpulan dari studi ini adalah TBJ metode Johnson-Toshack lebih tepat digunakan pada persalinan dengan ukuran lingkar perut $90-100 \mathrm{~cm}$, kecuali pada persalinan dengan selaput ketuban yang sudah pecah maka menerapkanTBJ berdasarkan formula Dare akan lebih tepat.
\end{abstract}

Kata kunci: Taksiran Berat Janin, Metode Johnson-Toshack, Formula Sederhana, Formula Dare

Angka Kematian Ibu (AKI) di Indonesia adalah tertinggi dibandingkan negara-negara ASEAN lainnya. Berdasarkan SDKI tahun 2007, Indonesia telah berhasil menurunkan Angka Kematian Ibu dari 334 per $100.000 \mathrm{KH}$ menjadi 228 per $100.000 \mathrm{KH}$ (Kemenkes RI, 2008 dalam Srianingsih, 2011). Namun AKI mengalami kenaikan yang signifikan yaitu sebesar 359 per $100.000 \mathrm{KH}$, sementara di Thailand hanya 44 per 100.000 KH,Malaysia 39 per 100.000 KHdan Singapura 6 per 100.000 KH (BPS, 2009 dalam Srianingsih, 2011). DI Provinsi DKI Jakarta tahun 2013 kejadian kematian Ibu sejumlah 93 orang dan yang disebabkan karena perdarahan adalah sebesar 31,18\%. Tahun 2014 terjadi penurunan Kematian Ibu sebesar 4,3\%. Namun untuk penyebab perdarahan naik menjadi 3,59\% (Dinas Kesehatan Provinsi DKI Jakarta, 2014).

Penyebab kematian ibu yang paling umum di Indonesia adalah penyebab obstetri langsung yaitu perdarahan (60-70\%). Sementara perdarahan pascapartum 4 kali lebih banyak daripada perdarahan antepartum ataupun perdarahan pada hamil muda (Manuaba dkk, 2008). Perdarahan pascapartum bisa disebabkan oleh atonia, retensio placenta, atau robekan jalan lahir. Guna mengantisipasi terjadinya atonia uteri, retensio placenta telah banyak diupayakan intervensi misalnya: pemberian 90 tablet besi selama hamil dan penatalaksanaan Manajemen Aktif Kala III, Kompresi Bimanual Interna (KBI) dan Kompresi Bimanual Ekterna (KBE). Sementara untuk mengantisipasi robekan 
jalan lahir setiap persalinan perlu tersedia alat eksplorasi porsio, dan bila kita telusur ke hulu adalah kemampuan penolong persalinan menaksir besarnya janin sehingga tidak menimbulkan distosia persalinan yang bisa menyebabkan robekan jalan lahir (Abdul Bari Saifuddin, 2010).

Taksiran Berat Janin (TBJ) selama kehamilan adalah salah satu cara yang bermanfaat untuk mengatasi masalah kesakitan dan kematian saat persalinan (Cunningham, 2005). Pendapat senada dikemukakan Mochtar (2000) yang menyatakan bahwa berat badan lahir akan mempengaruhi ketepatan penatalaksanaan persalinan dan hasilnya sehingga diharapkan dapat mengurangi angka kematian dan kesakitan pada ibu bersalin. Penaksiran berat badan janin dalam suatu penelitian juga masih dipandang perlu oleh banyak ahli kebidanan, meskipun demikian belum ada suatu metode yang berhasil membuat taksiran berat badan janin yang tepat. Di beberapa rumah sakit, masih dilakukan taksiran berat badan janin intrauterin dengan pengukuran tinggi fundus uteri. Ketepatan taksiran berat badan janin baik melalui pengukuran tinggi fundus uteri ataupun cara lain akan mempengaruhi penatalaksanaan persalinan (Subagio, 2000).

Ada berbagai cara untuk menentukan taksiran berat janin diantaranya adalah dengan pengukuran Tinggi Fundus Uteri (TFU), pemeriksaan ultrasonography (USG), pengukuran diameter biparietal (Pillitery, 2002 dalam Wahyuningsih, 2015). Bagi penolong persalinan seperti bidan, berat badan bayi mempunyai arti yang sangat penting dalam menentukan saat persalinan dan rujukan sehingga perlu dilakukan penaksiran berat badan janin yang akurat.

Teknik penaksiran berat janin yang paling banyak dilakukan oleh tenaga Bidan adalah dengan pengukuran tinggi fundus uteri. Pengukuran tinggi fundus uteri secara tepat dilakukan dengan skala centimeter. Tinggi fundus uteri mempunyai hubungan yang kuat dan bermakna dengan berat badan bayi dan merefleksikan pertumbuhan janin serta ukuran fetus lebih akurat (Rosmina, dkk, 2001). Pada pengukuran tinggi fundus uteri terdapat berbagai formula untuk menentukan taksiran berat janin diantaranya adalah formula Johnson-Toshack, Dare's, metode sederhana, Niswander, dan lain sebagainya (Farid Husin dkk, 2014).

Studi pendahuluan oleh peneliti pada 11 April 2015 saat kegiatan seminar di RSUP Fatmawati, dari 10 bidan peserta seminar yang diambil secara acak, bidan hanya mengenal Rumus Jhonson dan Toshack. Pada studi pendahuluan selanjutnya terhadap ibu bersalin di
RSUP Fatmawati mengenai akurasi formula TBJ dengan berat bayi yang dilahirkan, diketahui bahwa didapatkan selisih perhitungan antara TBJ dan BBBL yang besar dengan menggunakan formula Johnson-Toshack yakni 50\%. Selisih perhitungan TBJ terkecil dengan menggunakan metode Johnson-Toshack adalah 20 gram, dan selisih perhitungan TBJ terbesar adalah 975 gram.

Dari formula perhitungan TBJ yaitu formula Johnson-Toshack, formula Dare dan formula sederhana tidak memperhitungkan kondisi atau keadaan selaput ketuban. Sementara bila selaput ketuban masih utuh maka jumlah air ketuban akan berbeda dengan jumlah air ketuban pada klien yang selaput ketuban sudah ruptur. Jumlah air ketuban akan mempengaruhi tingginya fundus uteri.

Menurut Farid Husin (2014), janin dengan letak memanjang dan presentasi kepala dapat menggunakan tiga formula/ rumus/ metode untuk memperkirakan berat badan lahir janinyaitu; Formula Johnson dan Toshack [TBJ $=155 \mathrm{x}(\mathrm{TFU}-$ K)], Formula Sederhana [TBJ=100x(TFU-5)] dan Formula Dare [TBJ=TFUxLP].

\section{METODE}

Desain yang digunakan dalam penelitian ini adalah potong lintang (cross sectional design), dengan pengambilan data secara primer pada ibu bersalin di ruang bersalin RSUP Fatmawati Jakarta. Jumlah sampel 100 ibu bersalin, dengan kriteriainklusi: inpartu, hamil aterem, tunggal, presentasi kepala; dan kriteria eksklusi: hydramnion, anencephalus dan solusio placenta. Pengumpulan data dilakukan selama dua bulan yaitu pada 1 Agustus sampai 30 September 2015, dengan teknik accidental sampling. Data dianalisis secara statistik deskriptif untuk melihat estimasi deviasi. 


\section{HASIL}

\section{Tabel 1. Gambaran Karakteristik} Bersalin

\begin{tabular}{|c|c|c|c|}
\hline Variabel & Kategori & $\mathbf{f}$ & $\%$ \\
\hline \multirow{2}{*}{ Usia Ibu } & Fase Reproduksi Beresiko & 18 & 18 \\
\hline & Fase Reproduksi Sehat & 82 & 82 \\
\hline \multirow{2}{*}{$\begin{array}{l}\text { Pekerjaan } \\
\text { Ibu }\end{array}$} & Ibu Rumah Tangga & 87 & 87 \\
\hline & Ibu Bekerja & 13 & 13 \\
\hline \multirow{3}{*}{$\begin{array}{l}\text { Pendidikan } \\
\text { Ibu }\end{array}$} & Buta Huruf-SD & 2 & 2 \\
\hline & SMP-SMA & 86 & 86 \\
\hline & Pendidikan Tinggi & 12 & 12 \\
\hline \multirow{2}{*}{ Gravida } & Primi Gravida & 48 & 48 \\
\hline & Multi Gravida & 52 & 52 \\
\hline \multirow{2}{*}{ Paritas } & Primi Paritas & 50 & 50 \\
\hline & Multi Paritas & 50 & 50 \\
\hline \multirow{2}{*}{ Abortus } & Tidak Pernah Abortus & 88 & 88 \\
\hline & Ada Riwayat Abortus & 12 & 12 \\
\hline \multirow{3}{*}{$\begin{array}{l}\text { Lingkar } \\
\text { Perut }\end{array}$} & $<90 \mathrm{~cm}$ & 10 & 10 \\
\hline & $90-100 \mathrm{~cm}$ & 56 & 56 \\
\hline & $>100 \mathrm{~cm}$ & 34 & 34 \\
\hline \multirow{3}{*}{$\begin{array}{l}\text { Penurunan } \\
\text { Kepala }\end{array}$} & Tinggi & 68 & 68 \\
\hline & Sedang & 21 & 21 \\
\hline & Rendah & 12 & 12 \\
\hline \multirow{2}{*}{$\begin{array}{l}\text { Selaput } \\
\text { Ketuban }\end{array}$} & Positip & 56 & 56 \\
\hline & Negatif & 44 & 44 \\
\hline \multirow{3}{*}{$\begin{array}{l}\text { Jenis } \\
\text { Persalinan }\end{array}$} & Normal & 38 & 38 \\
\hline & Pervagina dengan Bantuan & 7 & 7 \\
\hline & Seksio Saesaria & 55 & 55 \\
\hline \multirow{3}{*}{$\begin{array}{l}\text { BB Bayi } \\
\text { Lahir }\end{array}$} & $<2500$ gram & 10 & 10 \\
\hline & 2500-3500 gram & 77 & 77 \\
\hline & $>3500$ garam & 13 & 13 \\
\hline
\end{tabular}

Tabel 2. Nilai Rata-rata Skor TBJ Metode Johnson-Toshak, Formula Sederhana dan Formula Dare

\begin{tabular}{lrrr}
\hline Variabel & \multicolumn{1}{c}{ Mean } & \multicolumn{1}{c}{ SD } & \multicolumn{1}{c}{ Min - Mak } \\
\hline Jhonson- & 44.50 & 461.47 & $(-) 1420-1345$ \\
$\begin{array}{l}\text { Thosak } \\
\text { Sederhana }\end{array}$ & 367.70 & 408.28 & $(-) 700-1700$ \\
Dare & $(-) 103.34$ & 514.46 & $(-) 1858-1336$ \\
\hline
\end{tabular}

Tabel 3. Perbedaan Deviasi TBJ berdasarkan Selaput Ketuban

\begin{tabular}{|c|c|c|c|c|c|}
\hline $\begin{array}{c}\text { Tehnik } \\
\text { Pengukur- } \\
\text { an }\end{array}$ & $\begin{array}{c}\text { Selaput } \\
\text { Ketu- } \\
\text { ban }\end{array}$ & $\begin{array}{c}\text { Obser- } \\
\text { vasi }\end{array}$ & Mean & SD & $\begin{array}{l}\text { Min - } \\
\text { Mak }\end{array}$ \\
\hline \multirow[t]{2}{*}{$\begin{array}{l}\text { Johnson- } \\
\text { Toshack }\end{array}$} & Utuh & 56 & (-)17.32 & 487.822 & $\begin{array}{l}(-) 1020 \\
-1345\end{array}$ \\
\hline & Pecah & 44 & 123.18 & 417.853 & $\begin{array}{r}(-) 1420 \\
-1020 \\
\end{array}$ \\
\hline \multirow[t]{2}{*}{ Sederhana } & Utuh & 56 & 293.39 & 429.601 & $\begin{array}{r}(-) 500- \\
1700\end{array}$ \\
\hline & Pecah & 44 & 462.27 & 362.46 & $\begin{array}{r}(-) 700- \\
1130 \\
\end{array}$ \\
\hline \multirow[t]{2}{*}{ Dare } & Utuh & 56 & (-)223.95 & 576.310 & $\begin{array}{r}(-) 1858 \\
-1336\end{array}$ \\
\hline & Pecah & 44 & 50.15 & 376.156 & $\begin{array}{r}(-) 1165 \\
-861\end{array}$ \\
\hline
\end{tabular}

Tabel 4. Perbedaan Deviasi TBJ berdasarkan Gravida

\begin{tabular}{|c|c|c|c|c|c|}
\hline $\begin{array}{c}\text { Tehnik } \\
\text { Pengukuran }\end{array}$ & Gravida & $\begin{array}{c}\text { Obser- } \\
\text { vasi }\end{array}$ & Mean & SD & $\begin{array}{l}\text { Min - } \\
\text { Mak }\end{array}$ \\
\hline \multirow[t]{2}{*}{$\begin{array}{l}\text { Johnson- } \\
\text { Toshack }\end{array}$} & Primi & 48 & 66.25 & 421.66 & $\begin{array}{r}(-) 1020- \\
1020\end{array}$ \\
\hline & Multi & 52 & 24.42 & 498.68 & $\begin{array}{r}(-) 1420- \\
1345\end{array}$ \\
\hline \multirow[t]{2}{*}{ Sederhana } & Primi & 48 & 366.67 & 366.35 & $\begin{array}{r}(-) 500- \\
1100\end{array}$ \\
\hline & Multi & 52 & 368.65 & 447.10 & $\begin{array}{r}(-) 700- \\
1700\end{array}$ \\
\hline \multirow[t]{2}{*}{ Dare } & Primi & 48 & $\begin{array}{r}(-) \\
92.67\end{array}$ & 553.74 & $\begin{array}{r}(-) 1858- \\
861\end{array}$ \\
\hline & Multi & 52 & $\begin{array}{r}(-) \\
113.19\end{array}$ & 480.62 & $\begin{array}{r}(-) 1232- \\
1336\end{array}$ \\
\hline
\end{tabular}

Tabel 5. Perbedaan Deviasi TBJ berdasarkan Riwayat Abortus

\begin{tabular}{|c|c|c|c|c|c|}
\hline $\begin{array}{c}\text { Tehnik } \\
\text { Pengukuran }\end{array}$ & $\begin{array}{l}\text { Riwayat } \\
\text { Abortus }\end{array}$ & $\begin{array}{l}\text { Obser- } \\
\text { vasi }\end{array}$ & Mean & SD & $\begin{array}{l}\text { Min - } \\
\text { Mak }\end{array}$ \\
\hline \multirow[t]{2}{*}{$\begin{array}{l}\text { Johnson- } \\
\text { Toshack }\end{array}$} & Tidak & 88 & 65.74 & 439.233 & $\begin{array}{r}(-) 1020- \\
1345\end{array}$ \\
\hline & $\mathrm{Ya}$ & 12 & $\begin{array}{r}(-) \\
111.25 \\
\end{array}$ & 600.553 & $\begin{array}{r}(-1420- \\
710 \\
\end{array}$ \\
\hline \multirow[t]{2}{*}{ Sederhana } & Tidak & 88 & 388.41 & 383.492 & $\begin{array}{r}-500- \\
1700\end{array}$ \\
\hline & $\mathrm{Ya}$ & 12 & 215.83 & 555.427 & $\begin{array}{r}(-) 700- \\
1000\end{array}$ \\
\hline \multirow[t]{2}{*}{ Dare } & Tidak & 88 & $\begin{array}{r}(-) \\
75.18\end{array}$ & 503.202 & $\begin{array}{r}(-) 1858- \\
1336\end{array}$ \\
\hline & $\mathrm{Ya}$ & 12 & 215.83 & 555.427 & $\begin{array}{r}(-) 700- \\
1000 \\
\end{array}$ \\
\hline
\end{tabular}

Tabel 6. Perbedaan Deviasi TBJ berdasarkan Lingkar Perut

\begin{tabular}{|c|c|c|c|c|c|}
\hline $\begin{array}{c}\text { Tehnik } \\
\text { Pengukuran }\end{array}$ & $\begin{array}{c}\text { Lingkar } \\
\text { Perut }\end{array}$ & $\begin{array}{c}\text { Obser- } \\
\text { vasi }\end{array}$ & Mean & SD & $\begin{array}{l}\text { Min - } \\
\text { Mak }\end{array}$ \\
\hline \multirow[t]{3}{*}{$\begin{array}{l}\text { Johnson- } \\
\text { Toshack }\end{array}$} & $<90 \mathrm{~cm}$ & 10 & 1.95 & 466.488 & $\begin{array}{r}(-) 455 \\
-985\end{array}$ \\
\hline & $\begin{array}{r}90-100 \\
\mathrm{~cm}\end{array}$ & 56 & $(-) 1.70$ & 459.155 & $\begin{array}{l}(-) 1420 \\
-1345\end{array}$ \\
\hline & $\begin{array}{r}>100 \\
\mathrm{~cm}\end{array}$ & 34 & 76.32 & 46.5425 & $\begin{array}{r}(-) 1020 \\
-830\end{array}$ \\
\hline \multirow[t]{3}{*}{ Sederhana } & $<90 \mathrm{~cm}$ & 10 & 435 & 349.643 & $\begin{array}{r}0- \\
1000\end{array}$ \\
\hline & $\begin{array}{r}90-100 \\
\mathrm{~cm}\end{array}$ & 56 & 318.04 & 412.070 & $\begin{array}{l}(-) 700 \\
-1700\end{array}$ \\
\hline & $\begin{array}{r}>100 \\
\mathrm{~cm} \\
\end{array}$ & 34 & 429.71 & 417.398 & $\begin{array}{r}(-) 500 \\
-1130 \\
\end{array}$ \\
\hline \multirow[t]{3}{*}{ Dare } & $<90 \mathrm{~cm}$ & 10 & 393.5 & 340.4779 & $\begin{array}{r}(-) 104 \\
-852\end{array}$ \\
\hline & $\begin{array}{r}90-100 \\
\mathrm{~cm}\end{array}$ & 56 & $\begin{array}{r}(-) \\
51.32\end{array}$ & 422.420 & $\begin{array}{l}(-) 1165 \\
-1336\end{array}$ \\
\hline & $\begin{array}{r}100 \\
\mathrm{~cm}\end{array}$ & 34 & $\begin{array}{r}(-) \\
335.15\end{array}$ & 574.676 & $\begin{array}{r}(-) 1858 \\
-597\end{array}$ \\
\hline
\end{tabular}

\section{PEMBAHASAN}

Deviasi TBJ dengan menerapkan metode Johnson-Toshack mendapatkan rerata 44.50 gram, perhitungan TBJ cenderung lebih besar dari berat badan bayi ketika lahir. Hasil penelitian ini sama dengan hasil penelitian yang 
dilakukan oleh Rosmina dkk (2003) di Manado yang dikutip oleh Gayatri (2006) menyimpulkan bahwa metode Johnson-Toshack mengestimasi berat badan lahir yang didapatkan cenderung lebih tinggi daripada berat badan lahir aktual.Bila lingkar perut ibu hamil $<90 \mathrm{~cm}$ maka rerata deviasi yaitu 195 gram, bila lingkar perut klien antara 90-100 cm maka didapatkan rerata deviasi adalah1.70 gram, dan bila lingkar perut $>100 \mathrm{~cm}$ maka didapatkan rerata deviasi sebesar 76.32 gram. Hal ini menggambarkan bahwa metode Johnson-Toshack lebih tepat digunakan pada klien yang memiliki ukuran lingkar perut sebesar 90-100 cm karena memiliki rerata deviasi lebih kecil.

Deviasi TBJ Formula Sederhana, mendapatkan rerata 367.70 gram, sama dengan metode Johnson-Toshack formula ini juga memiliki kecenderungan perhitungan TBJ yang lebih besar dari berat bayi ketika lahir. Adanya perbedaan rerata deviasi menggunakan metode ini pada klien dengan selaput ketuban yang masih utuh yaitu 293.39 gram dan klien dengan selaput ketuban yang sudah pecah 462.27 gram. Hal ini menggambarkan bahwa formula sederhana cenderung lebih tepat digunakan pada klien yang selaput ketuban masih utuh, karena deviasi lebih kecil.

Perhitungan deviasi TBJ Formula Dare, menghasilkan TBJ yang cenderung lebih kecil, hal ini dapat dilihat dari rerata deviasi adalah (-) 103.34 gram. Namun sama dengan formula lainnya dapat juga dalam penerapan formula Dare menghasilkan TBJ yang lebih besar dari pada ketika bayi lahir, hal ini bisa dilihat dari range deviasi yang maksimal adalah 1336 gram.

Hasil penelitian juga mendapatkan adanya perbedaan rerata deviasi menggunakan metode ini pada klien dengan selaput ketuban yang utuh yaitu (-) 223.95 gram dan klien dengan selaput ketuban pecah 50.15 gram. Hal ini menggambarkan bahwa formula Dare cenderung lebih tepat digunakan pada klien yang selaput ketuban pecah, karena deviasi lebih kecil.

\section{DAFTAR PUSTAKA}

Abdul Bari Saifuddin. 2010. Ilmu Kebidanan. Yayasan Bina Pustaka Sarwono Prawirohardjo.

Abdul Bari Saifuddin. 2010. Buku Panduan Praktis Pelayanan Kesehatan Maternal Neonatal. Yayasan Bina Pustaka Sarwono Prawirohardjo.

BPS. 2012. Survei Demografi dan Kesehatan Indonesia (SDKI). Jakarta.
Hasil penelitian juga mendapatkan adanya perbedaan rerata deviasi menggunakan metode ini pada klien dengan primi gravida yaitu (-) 92.67 gram dan klien multi gravida adalah (-) 113.19 gram. Hal ini menggambarkan formula Dare cenderung lebih tepat digunakan pada klien yang primi gravida karena deviasi lebih kecil.

Hasil penelitian juga mendapatkan adanya perbedaan rerata deviasi menggunakan metode ini pada klien dengan riwayat abortus yaitu ()309.83 gram dan klien tanpa riwayat abortus adalah (-) 75.18 gram. Hal ini menggambarkan formula Dare cenderung lebih tepat digunakan pada klien yang tanpa riwayat abortus karena deviasi lebih kecil.

Hasil penelitian juga mendapatkan adanya perbedaan rerata deviasi menggunakan metode ini pada klien dengan lingkar perut. Bila lingkar perut $<90 \mathrm{~cm}$ rerata deviasi yaitu 393.5 gram dan bila lingkar perut klien 90-100 $\mathrm{cm}$ diperoleh rerata deviasi adalah (-) 51.32 gram, Bila lingkar perut $>100 \mathrm{~cm}$ didapat rerata deviasi sebesar (-) 335.15 gram. Hal ini menggambarkan formula Dare cenderung lebih tepat digunakan pada klien yang memiliki ukuran lingkar perut sebesar 90$100 \mathrm{~cm}$ karena memiliki rerata deviasi lebih kecil.

\section{SIMPULAN}

Taksiran berat janin metode JohnsonToshack lebih tepat digunakan pada persalinan dengan ukuran lingkar perut 90-100 cm, kecuali pada persalinan dengan selaput ketuban yang sudah pecah maka menerapkan taksiran berat janin berdasarkan formula Dare akan lebih tepat.

\section{SARAN}

Penelitian ini merekomendasikan peluang untuk mengembangkan formula/ metode yang sudah ada agar estimasi TBJ lebih akurat.

Cunningham, F. Et al. 2006. Obstetric William. Jakarta: EGC.

Djamhoer Martaadisoebrata, R. Sulaiman Sastrawinata, Abdul Bari Saifuddin. 2005. Bunga Rampai Obstetri dan Ginekologi Sosial. Yayasan Bina Pustaka Sarwono Prawirohardjo.

Farid Husin Dr. 2014. Asuhan Kehamilan Berbasis Bukti. Sagung Seto. 
Notoatmodjo Soekidjo. 2013. Pendidikan dan Perilaku Kesehatan. Jakarta: Rineka Cipta.

Gayatri, Dewi dan Afriyanti Y. 2004. Perbandingan Beberapa Rumus Untuk Memprediksi Berat Badan Lahir Berdasarkan Pengukuran Tinggi Fundus Uteri. Jurnal Keperawatan Indonesia, Vol 8, No 1, Maret 2004 http://www.jki.ui.ac.id/index.php/jki/art icle/viewFile/142/pdf_116 (Diakses pada 12 April 2015)

Gayatri, Dewi dan Afriyanti Y. 2006. Validasi Rumus Taksiran Berat Janin (TBJ) Untuk Prediksi Berat Badan Lahir Berdasarkan Tinggi Fundus Uterus Ibu Hamil. Jurnal Keperawatan Indonesia. http://www.jki.ui.ac.id/index.php/jki/articl e/viewFile/169/pdf_91 (Diakses pada 12 April 2015).

Helen Varney, Jan M Kriebs, Carolyn L Gregor, alih bahasa oleh Laily Mahmudah dan Gita Tri Setyati. 2002. Asuhan Kebidanan. Volume 2, Edisi 4. EGC.

Jurusan Kebidanan Poltekkes Kemenkes Jakarta I. 2012. Kurikulum Institusi.

Rusdy, dkk. 2014. Perbandingan Rumus Johnson-Tohsach Dengan Rumus South Africa Dalam Menentukan Taksiran Berat
Janin Di Puskesmas Kecamatan Pasar Rebo, Jakarta Timur. Jurnal Keperawatan, Vol 2, No 1, April 2014.

http://www.journal.ui.ac.id/index.php/eJKI /article/viewFile/3185/2477 (Diakses pada 12 April 2015).

Srianingsih. 2011. Beberapa Faktor Determinan Yang Meningkatkan Risiko Terjadinya Kematian Ibu Akibat Perdarahan Di Pulau Lombok Porvinsi Nusa Tenggara Barat: Studi Kasus-Kontrol.

http://www.pps.unud.ac.id/thesis/detail290-beberapa-faktor-determinan-yangmeningkatkan-risiko-terjadinya-kematianibu-akibat-perdarahan-di-pulau-lomokprovinsi-nusa-tenggara-barat-studikasuskontrol.html (Diakses pada 7 Mei 2015).

Wahyuningsih, SW. 2015. Perbedaan Taksiran Berat Janin Dengan Ultrasonography (USG), Rumus Mc. Donald dan Metode Niswander di Rumah Sakit Aprilia Cilacap.

http://www.digilib.stikesmuhgombong.ac.i d/files/disk1/31/jtstikesmuhgo-gdlsriwalyati-1502-1-bab1-3-w.pdf (Diakses pada 18 April 2015). 